\title{
IT UAF CLOUD: A Trusted Storage Architecture for Cloud Computing
}

\author{
Hafiza Mahrukh Shahzadi ${ }^{1, *}$ Shazia Riaz ${ }^{2}$ \\ ${ }^{1}$ Department of Computer Sciences, Government Collage Women University Faisalabad, Pakistan. \\ ${ }^{2}$ Department of Computer Sciences, Government Women University Faisalabad, Pakistan \\ *Corresponding author's email: mahrukhfarooq628 [AT] gmail.com
}

\begin{abstract}
The issue for the understudies and clients to where they need to situate to their records and critical stuff. In this way we attempt to determine this issue by building up an Online Cloud known "It Uaf Cloud". When we say cloud, we have to comprehend that word 'cloud' is a similitude for Internet and along these lines it just means a type of web-based registering. It depends on the model of shared registering assets rather than neighborhood servers, stockpiling gadgets that are utilized to deal with client applications. Cloud accordingly tackle more than what customary methods for registering could accomplish without requiring physical server and capacity frameworks at the area you are in. It has a colossal potential and offer extraordinary preferences clients. Cloud frameworks in a general sense give access to extensive pools of information and computational assets through an assortment of interfaces comparative in soul to existing lattice and HPC asset administration and programming frameworks. These kinds of frameworks offer another programming focus for versatile application engineers and have picked up prevalence in the course of recent years. Nonetheless, most distributed computing frameworks in task today are exclusive, depend upon foundation that is imperceptible to the examination network, or are not unequivocally intended to be instrumented and changed by frameworks specialists. Cloud suppliers hypothetically offer their clients boundless assets for their applications on an on-request premise. In any case, versatility isn't just controlled by the accessible assets, yet in addition by how the control and information stream of the application or administration is outlined and actualized.
\end{abstract}

Keywords-Storage, Online Cloud, Data Protection, Safe storage

\section{INTRODUCTION}

Our Purpose is to make a stage for every one of the clients who will transfer their documents and need to share their records to anybody they need. Cloud implies that rather than all the PC equipment and programming you're utilizing sitting on your work area, or some place, it's given to you as an administration and got to over the Internet, as a rule in a totally consistent manner. Precisely where the equipment and programming are found and how everything functions doesn't make a difference to you, the client - it's only some place up in the shapeless "cloud" that the Internet speaks to.

Distributed computing is a popular expression that involves diverse things to several individuals. For a few, it's simply one more method for portraying IT (data innovation) "outsourcing"; others utilize it to mean any processing administration gave over the Internet or a comparative system; and approximately characterize it as any bought in PC profit you utilize that sits outside your firewall. Cloud has as of late risen as another worldview for facilitating and conveying administrations over the Internet. Cloud is appealing to clients and entrepreneurs as it wipes out the necessity for clients to prepare for provisioning, and enables them to begin from the little and increment assets just when there is an ascent in administration request. A stage which have the interface for all clients and understudies of each subject to come and transfer their records of any sort e.g. pictures, recordings. Also, secure them in their organizers, if any client needs to share their envelope or record to other, they can. Cloud is a sort that depends on shared processing assets instead of having nearby servers or individual gadgets to deal with applications. In its most basic portrayal, cloud is taking administrations ("cloud administrations"). Applications, stockpiling and different administrations are gotten to through the Web. The managements are transferred.

\subsection{Purpose}

While the genuine reason may rely upon who you ask, it is plausible that the reason you are fills numerous needs. 
The significant motivation behind me to build up this cloud site is to give the clients to their capacity and some others are:

- Cloud suppliers by and large guarantee most extreme uptime which implies upgraded accessibility to clients. Just web associated is required to utilize an application whenever, anyplace. What's more, to add to that there are applications that even work disconnected

- It likewise serves for capacity

- User can share the records and information of any sort

- It fills in as an extra medium for coordinated effort and the trading of records

- It additionally gives security of information of clients

- It enables most recent adaptations of utilization to reach to clients instantly in this manner expanding efficiency

- It enables versatility and more prominent adaptability to clients as they can stay aware of the application at any area around the globe through their web empowered gadgets like tablets, cell phones and workstations. This beyond any doubt unravels numerous a thing for efficiency of business.

When we say cloud, we have to comprehend that word 'cloud' is an illustration for Internet and along these lines it just means a type of web-based registering. It depends on the model of shared processing assets instead of nearby servers, stockpiling gadgets that are utilized to deal with client applications. Cloud along these lines illuminate more than what customary methods for figuring could accomplish without requiring physical server and capacity frameworks at the area you are in. It has a colossal potential and offer extraordinary favourable circumstances to clients.

\section{LITERATURE SURVEY}

Spoorthy et al. 2014 reported in A Survey on Data Storage and Security in Cloud Computing distributed computing has been imagined as the cutting-edge design of IT undertaking. Cloud processing moves the application programming and information bases to the expansive server farms, where the administration of the information and administrations may not be completely dependable. This postures numerous new security challenges which have not been completely executed. In this paper, we for the most part center around viewpoints for giving security to information stockpiling in cloud, too design for information stockpiling that are actualized by other specialist organizations sellers in cloud, key focuses for demonstrating security for information stockpiling.

Anisha Tandon, 2014 reported in Implementing \& Developing Cloud Computing on Web Application web based distributed computing, its qualities, benefit models, and organization models being used today. We likewise talked about the advantages and difficulties of distributed computing and the noteworthiness of adaptability and versatility in a cloudbased condition. In this paper we additionally center on issues and favorable circumstances for web and cloud-based applications; we likewise point out the different troubles related with dynamic updates for such applications, present and design bearings for future work. Distributed computing [1] is developing as a worldview for facilitating Internet-scale applications in gigantic registering foundations. In specific, IT administrations are moving from big business scale figuring frameworks to distributed computing foundations that is pay-for-benefit enormous server farms with a huge number of machines. Distributed computing alludes to those administrations and applications that will be conveyed in the web cloud, and the principle truth is that, by and large, the gadgets that are utilized to access such administrations also, applications which don't require any uncommon applications.

Santosh Kumar and R. H. Goudar et al. 2012. Distributed computing is the improvement of parallel processing, disseminated figuring, framework registering and virtualization innovations which characterize the state of another time. Distributed computing is a developing model of business figuring. In this paper, we investigate the idea of cloud engineering and contrasts distributed computing and lattice registering. We likewise address the attributes and utilizations of a few well-known distributed computing stages. In this paper, we mean to pinpoint the difficulties and issues of distributed computing. We recognized a few difficulties from the distributed computing reception point of view and we likewise featured the cloud interoperability issue that merits generous further innovative work. Be that as it may, security and protection issues present a solid boundary for clients to adjust into distributed computing frameworks. In this paper, we research a few distributed computing framework

Sultan Ullah et al. 2014. The distributed storage gives a slightest cost method for information stockpiling for the little and substantial ventures over the globe. Be that as it may, the principle blockade to broad appropriation of distributed storage is the pool of trust in the innovation by its client. The information is put away on different servers and the area is hidden from the clients and they are no more responsible for the information. This unmistakable element of the distributed storage presents numerous security and trust challenges. In this paper we present a confided in engineering of cloud information stockpiling. The design shows a one of a kind method for secure capacity and getting to of information from the cloud 
server farm. It likewise guaranteed that just approved client will have the capacity to get to the information. Furthermore, if there is any infringement of the security parameter at the server farm, the information will in any case be protected i.e. the information will be put away in encoded frame.

\subsection{Advantages of the New System}

It allows mobility and greater flexibility to users as they can keep up with the application at any location around the world via their internet-enabled devices like tablets, smartphones and laptops.

- The most important benefit one can get by using cloud is cost saving

- We do the system maintenance

- Reliability

- Less personal training is needed

\subsection{Scope}

This proved to be very useful for all the users. Cloud storage can be delineated as storing of data and information on the servers (commonly known as cloud). This service of cloud storage is mostly Require these services buy or lease storage space from the vendor's .Above all, we hope to provide a comfortable user experience. Cloud computing is one of the most talked about IT trends today. The word 'Cloud' refers to the widespread internet, which means Cloud Computing is an internet based computing where services are delivered to the users via internet.

\section{PROJECT DESCRIPTION}

The undertaking titled "IT UAF CLOUD" is composed utilizing PHP and MySQL keeps running under PHP Frame.

The undertaking contains 7 fundamental modules.

- Registration

- Category (Folders)

- Uploads

- Dashboard

- Share Files

- Share Folders

- Share link with mail

a. Registration module:

Enlistment module let the general population ready to end up cloud application clients by including their essential individual data.

b. Category (folder) module:

This module enables user to categories his files. User can create folders (category). To add related files, such as files about furniture will be inside Furniture folder.

c. Upload module:

Upload component lets operators enable to upload any category of file for example: image, video, audio, Text, document files etc.

\section{d. Dashboard module:}

Dashboard modules demonstrates details of use. For example, add up to space utilized, accessible space and aggregate documents transferred. Expansion segment for administrator demonstrates add up to clients.

\section{e. Share files module:}

Clients can share their records to different people groups. Utilize can secure record with secret key. With the goal that just approves clients can get to shared documents. This module produces a connection witch client imparts to other people.

\section{f. Share folder module:}

Clients can share their envelope to people groups. Utilize can secure organizer with secret word. With the goal that just approves clients can get to shared organizer documents. This module produces a connection witch client imparts to other people.

g. Share file $\&$ folder using mail module:

This module let the user enable to share generated share link to different emails. 


\section{PROBLEM DESCRIPTION}

We realize that there is enormous issue for all individuals how to keep records with us whenever. So, cloud settle our concern and it helps, Anytime, Anywhere, Access, by selecting cloud administrations you can get to your reports, documents, applications with no area and time imperative. Also, you can impart the docs to other people. Everybody is available on worldwide town (internet). It would be accessible whenever anyplace with no expense aside from of having web and checked personality of clients. So, this application will resolve these issues.

\section{EXISTING SYSTEM}

The idea of time-shared remote administrations isn't new, distributed computing foundations utilize new innovations and administrations, some of which haven't assessed as for security. Security is viewed as a standout amongst the most basic perspectives in ordinary figuring and it isn't distinctive for distributed computing because of the affectability and significance of information put away in the cloud.

\subsection{Drawbacks}

A portion of the downsides are:

Cloud registering frameworks are web based, which implies your entrance is completely subject to your Internet association.

Of course, your cloud specialist organization is required to oversee and shield the fundamental equipment foundation of an arrangement, anyway remote access is your obligation and, regardless, no framework is impeccably secure obviously, your cloud specialist co-op is relied upon to oversee and protect the basic equipment foundation of a sending, anyway remote access is your duty and, regardless, no framework is flawlessly secure.

Depending on the cloud supplier, you may confront limitation on accessible applications, working frameworks and foundation alternatives.

It might be conceivable that the information for a particular purpose of time can't be distinguished, information might be scattered around various servers.

Cloud figuring innovation permit cloud servers to dwell anyplace therefore the client may not know the physical area of the server used to store and process their information and applications.

\subsection{Proposed Solution:}

It is hard to note down every one of the issues physically. Rather it is chosen to build up an "IT UAF CLOUD" to facilitate the task. A framework is required which is being equipped for disposal every one of the issues and end up valuable to clients and subsequently the new framework is inferred. Here we get an alternate view from various clients.

\subsubsection{Development Requirements:}

\section{Hardware:}

The hardware used for the development of the project is:

\begin{tabular}{|c|c|}
\hline PROCESSOR & : 1.9Ghz Dual Core Processor \\
\hline RAM & $: \quad$ 4GB RAM \\
\hline MONITOR & $640 * 480$ '16 Bit-color' \\
\hline HARD DISK & $500 \mathrm{~GB}$ \\
\hline FLOPPY DRIVE & $: \quad 1.44 \mathrm{MB}$ \\
\hline CD DRIVE & LG $52 \mathrm{X}$ \\
\hline KEYBOARD & : STANDARD 102 KEYS \\
\hline MOUSE & 3 BUTTONS \\
\hline
\end{tabular}

\section{Software:}

The software used for the development of the project is:

\begin{tabular}{lcll} 
OPERATING SYSTEM & $:$ & \multicolumn{2}{l}{ Windows 7} \\
ENVIRONMENT & & $:$ & Phpstorm / Sublime \\
LANGUAGE & $:$ PHP & \\
BACKEND & $:$ & MYSQL \\
ONLINE DOMAIN & $:$ & theitobjects.com
\end{tabular}




\section{METHODOLOGY}

\subsection{Use case Diagram of user:}

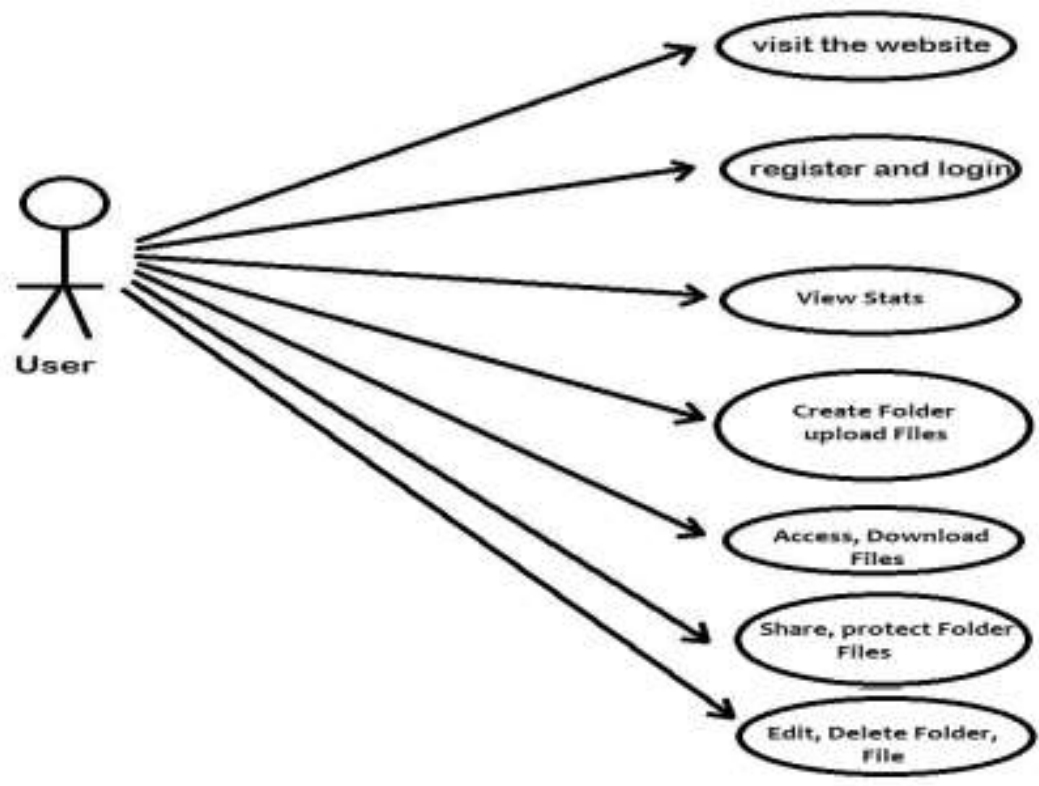

Use case of user description:

Figure 1: User Use Case

\subsection{Use case diagram of admin:}

\begin{tabular}{|l|l|}
\hline \multicolumn{2}{|l|}{ This use case shows how a user uses a CLOUD System. } \\
\hline Actors: & User \\
\hline Preconditions: & $\begin{array}{l}\text { The user must be registered if he/she want to get } \\
\text { services of cloud environment. }\end{array}$ \\
\hline Basic Flow of Event & $\begin{array}{l}\text { Then user login to the system. See the statistics of his } \\
\text { available space, used space and number of files } \\
\text { he/she uploaded }\end{array}$ \\
\hline Key Scenarios & $\begin{array}{l}\text { The user must take care in posting. If he/she. } \\
\text { Uploads illegal content will be blocked. }\end{array}$ \\
\hline Post conditions & $\begin{array}{l}\text { Successful Completion: The user has finished } \\
\text { Uploading file under given limit of 10 GB. } \\
\text { failure Completion: The user did not enter details } \\
\text { correct, incorrect password etc. }\end{array}$ \\
\hline
\end{tabular}


The Admin has the following sets of use cases:

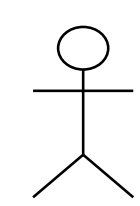

Admin

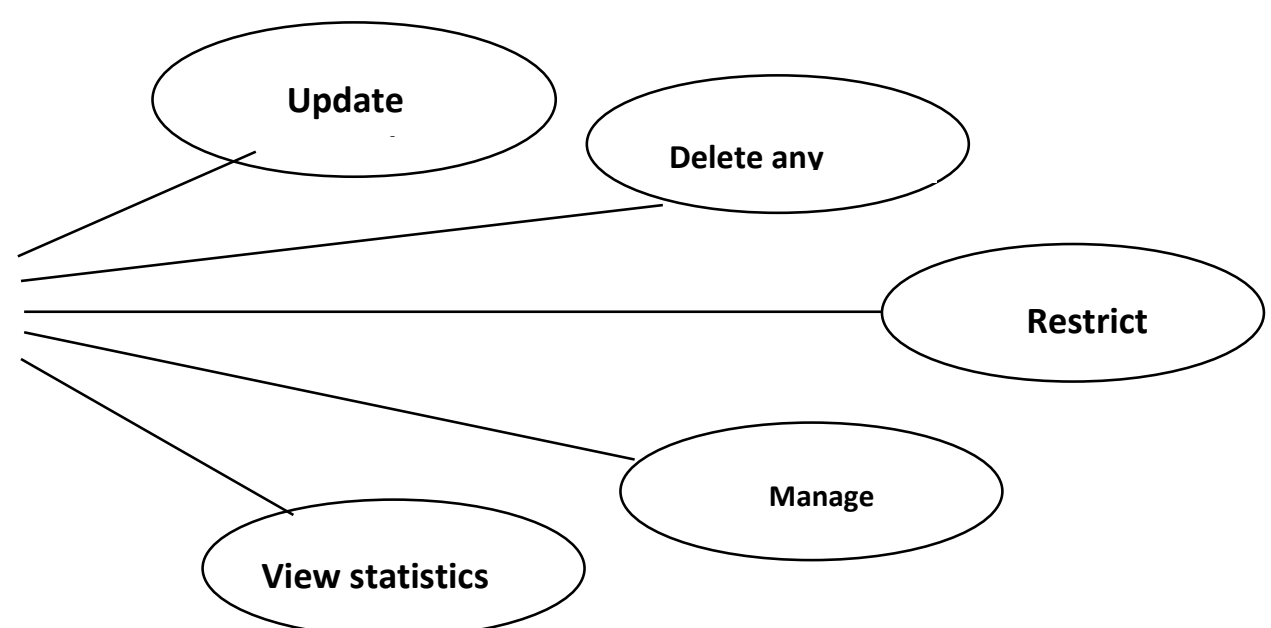

Figure 2: Admin Use Case

\section{Use case of admin description:}

This use case shows how a admin of an IT UAF CLOUD to manage the system

\begin{tabular}{|c|c|}
\hline Actor & Admin \\
\hline preconditions & $\begin{array}{l}\text { Admin can view the all details of the Users that are stored in the } \\
\text { database }\end{array}$ \\
\hline Basic flow of event & $\begin{array}{l}\text { Admin can log in the user admin can change delete or update the } \\
\text { posts. Admin can view the Users lists. Admin can view the file } \\
\text { or folders of other users. Admin can logout the User from the } \\
\text { Forum. }\end{array}$ \\
\hline Alternate flow & $\begin{array}{l}\text { If the User enters the wrong data admin can delete user from the } \\
\text { website }\end{array}$ \\
\hline Key scenario & Admin can accept and reject the data of user. \\
\hline Post conditions & $\begin{array}{l}\text { Successful Completion: The admin has finished to manage the } \\
\text { system. }\end{array}$ \\
\hline Special Requirement & $\begin{array}{l}\text { Users must be connected to the internet } \\
\text { Users should use webs browsers such as google chrome, } \\
\text { firefox, Opera and internet Explorer. }\end{array}$ \\
\hline
\end{tabular}




\subsection{Class Diagram:}

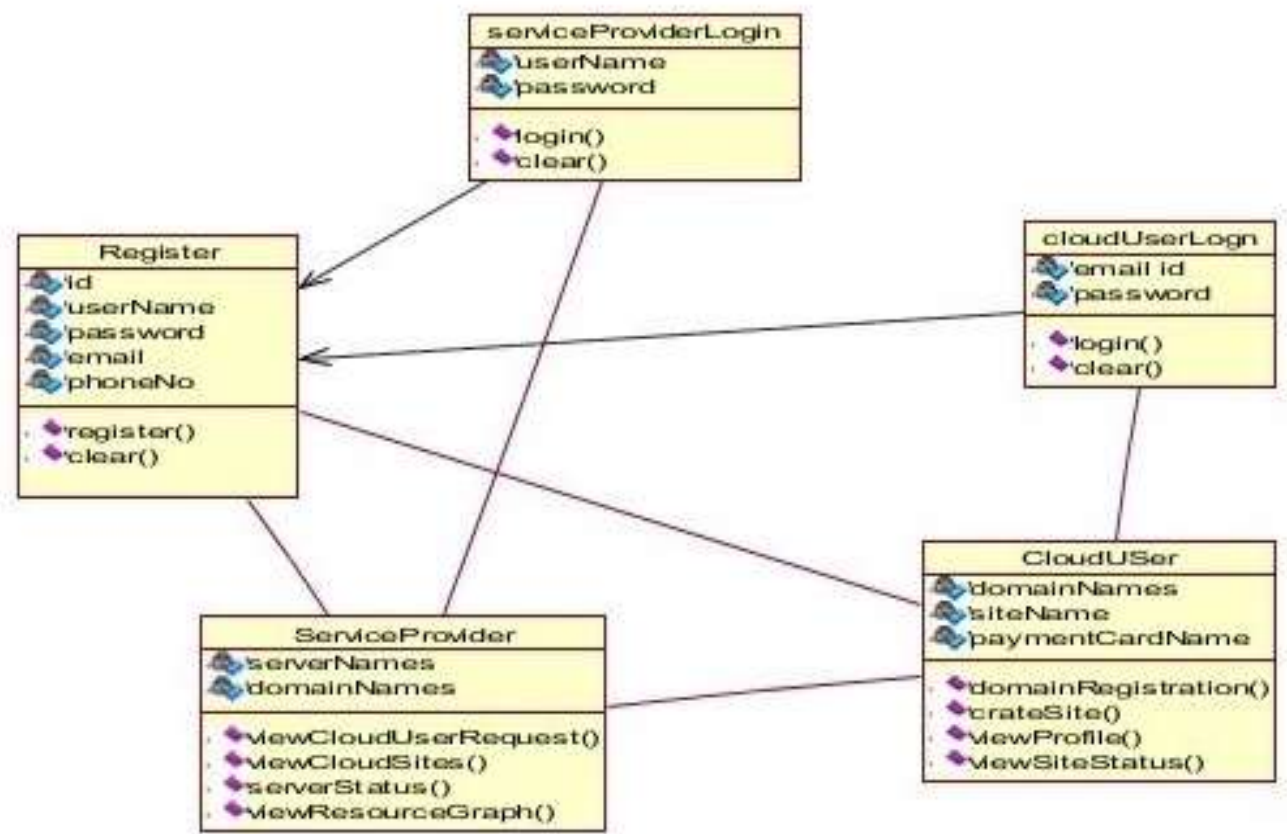

\subsection{Data Flow Diagram:}

Figure 3: Class diagram for overall system

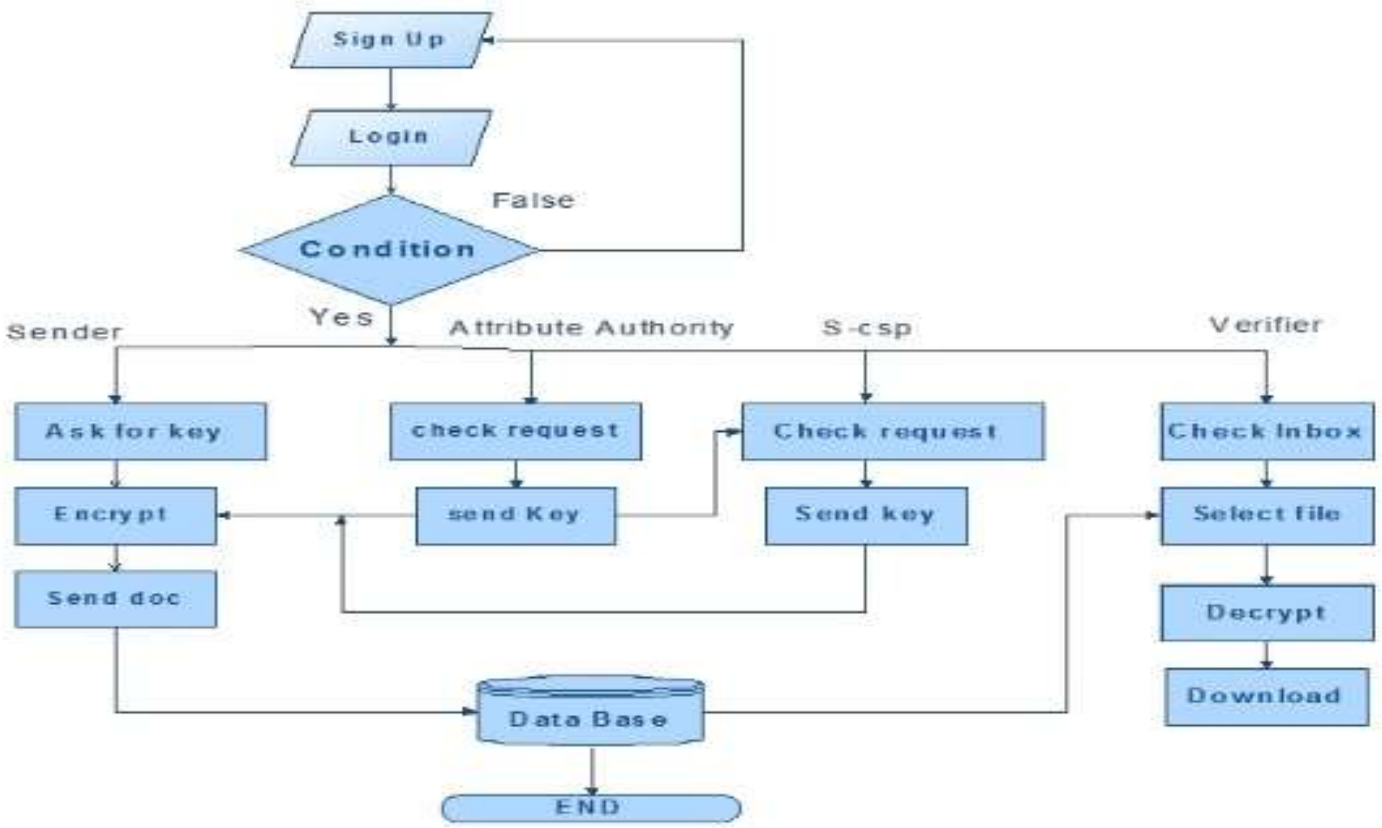

Figure 4: Data flow diagram for database 


\subsection{Sequence Diagram:}

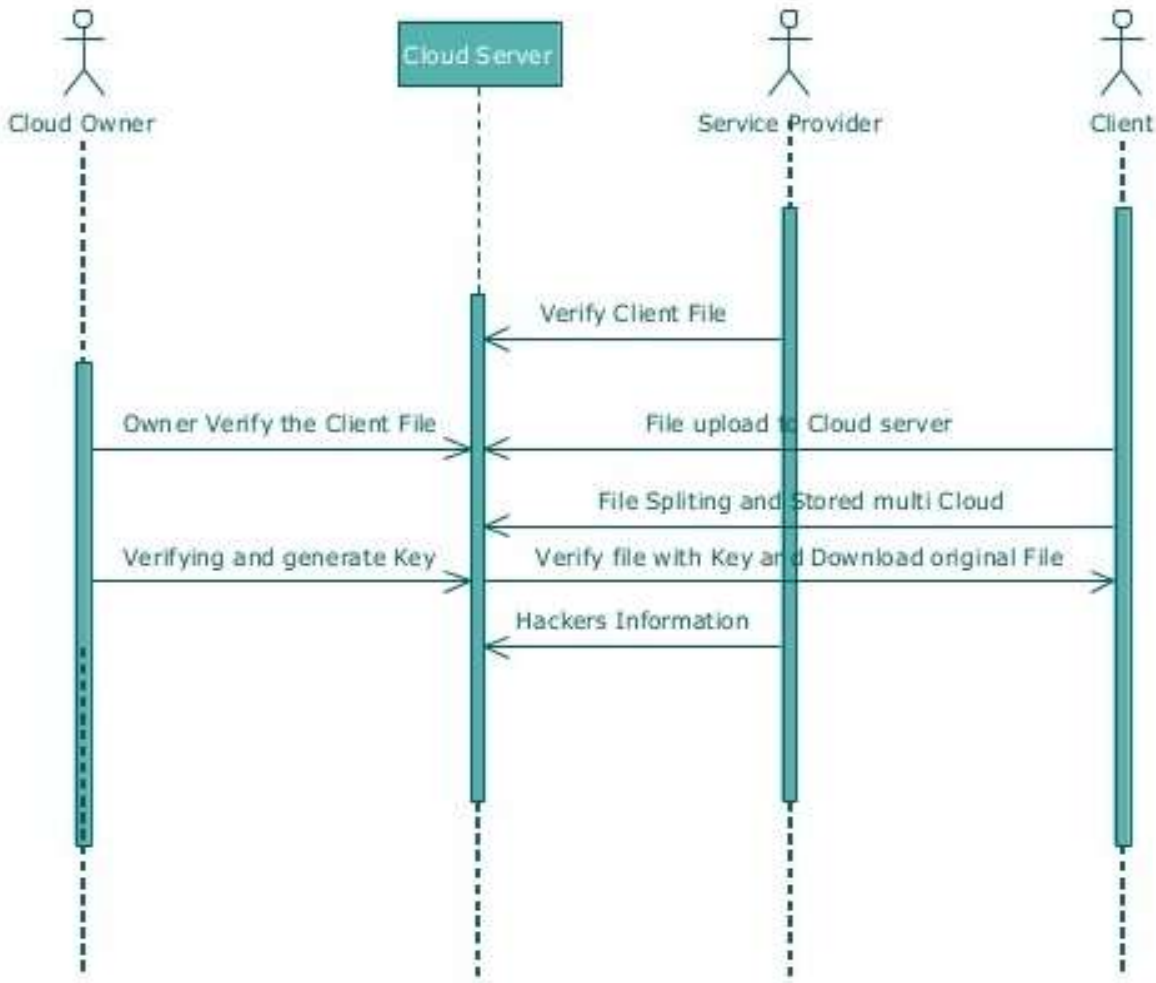

Figure 5: Sequence diagram for overall system

\section{RESULTS \& DISCUSSION}

Most importantly, to actualize the "IT UAF CLOUD" requires a web-server to convey the IT UAF CLOUD data from the framework to the customer. The server will running numerous server programs, so a steady situation is required. Linux was been the activity framework.

IT UAF CLOUD is a modules base framework, so the plan of the framework ought to be founded on fundamental modules as could be expected under the circumstances. There are a few points of interest of compose the program into modules structures. The software engineer can include or expel the capacity (modules) all the more effortlessly. The software engineer just thinks about how to programming with modules, yet they don't require to comprehend the profound of IT UAF CLOUD. What's more, the codes are less demanding to peruse by other individual. And furthermore IT UAF CLOUD is outline to Multi-Language and Multi-Interface. Since the Internet is worldwide. Any framework running on the Internet is required to internationalization to permit the most peruser getting less demanding to comprehends and get the most refresh data without the dialect issue. So the plan of IT UAF CLOUD must give a system that permits showing on various dialect and the client can choose their favored dialect. The stage is most likely rely upon the fulfillment of clients, for this reason there would test methods ought to be connected to convey the $100 \%$ viable reaction to clients. Keeping in mind the end goal to satisfy this necessity we begin from unit testing in which the littlest testable parts of an application, called units, are separately and autonomously examined for appropriate activity. In particular testing, testing is the entire code questions as delivered by the compiler when worked from source. A library might be made out of a solitary accumulated protest or a few gathered items.

It would be gainful on the off chance that we apply all these Consistency and Integrative calculations for fulfillment of clients. In Response time, we will check and equalization the aggregate time it takes from when a client influences a demand until they to get a reaction. While completing a heap or execution test we have to discover how our application, site and API dealing with every one of the solicitations. In calculation testing we will watch out for time and multifaceted nature calculations of all modules utilized in the framework. In general, in the planning and improvement stage, we don't need to confront any obstacle. After usage it very well may be assessed on all the test on close to home check, at that point every one of the slip-ups which we need to face will be enhance in upkeep stage.

\subsection{Outputs of the Developed System:}

1. Speed and Accuracy

2. Efficient and flexible

3. Managerial and Acceptable 

4. User Friendly
5. Security
6. Economy
7. Time Saving
8. Neat and Clean Setup

\subsection{User Manual:}

A user guide or user's guide, also commonly known as a manual, is a technical communication document intended to give assistance to people using a particular system.Our User Manual of UAF CLOUD is:

\subsection{Home page:}

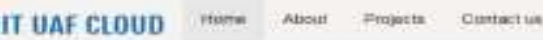

\section{More than just sharing and storage}

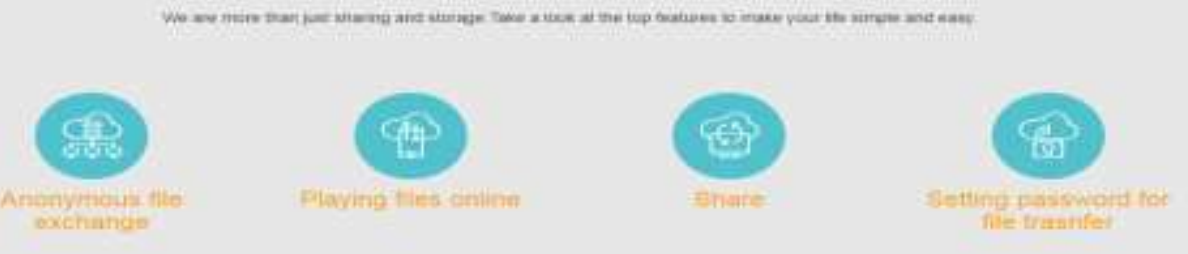

\subsection{Admin Dashboard:}

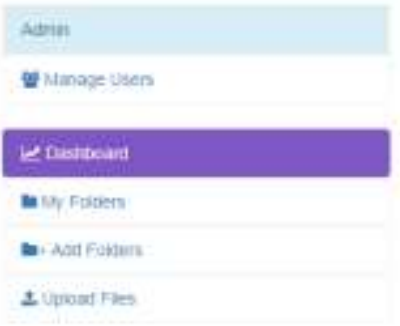

\section{Welcome, Admin}
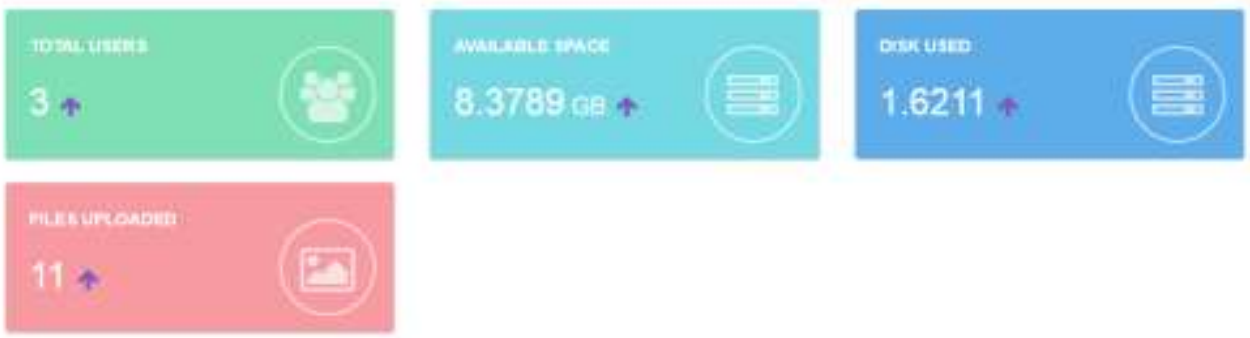

IT LAF Clous 301 : Aa Aights Reservot 


\subsection{Manage Users:}

IT UAF CLOUD

Admin C. Logout

\begin{tabular}{|c|}
\hline Aarin \\
\hline As Mangge Useru \\
\hline le Dosshboard \\
\hline - Mly Folders \\
\hline E-Add Foldens \\
\hline
\end{tabular}

\section{Users}

\begin{tabular}{|c|c|c|c|c|c|c|c|}
\hline * & Name & Email & Password & Space Used & Type & Created & Action \\
\hline 1 & Sarah Hafeez & sarahateez23@gmail.com & 123456 & $0.2154 \mathrm{Ge}$ & mets & $2018-04-12: 22: 30: 23$ & a \\
\hline 2 & admin & adminfegrnail com & 123456 & 1.6211 15e & entar & $20110-04-1222: 55: 35$ & \\
\hline 3 & adnen & usergagmaik com & 123456 & 008 & fines & 2018-04-06 07:38:41 & a \\
\hline
\end{tabular}

\subsection{My Folders:}

\section{IT UAF CLOUD}

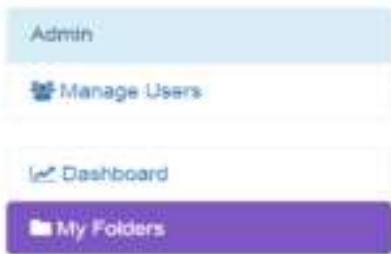

- Add Foiden

\pm Upioad Files

Adimin Co Logout

\section{My Folders}

ntie

1 an Miciosat office

2. Ba Businnss

3. ENature

$4 . \quad$ घाт

\section{Created}

2018-04-12:22:47:42

2018:04:25 23:06:45

2018-04-25:23:06:27

2018-04:25 23:07:06
Action

뭄ㅁ

ด्व

드료

달 


\subsection{Upload files:}

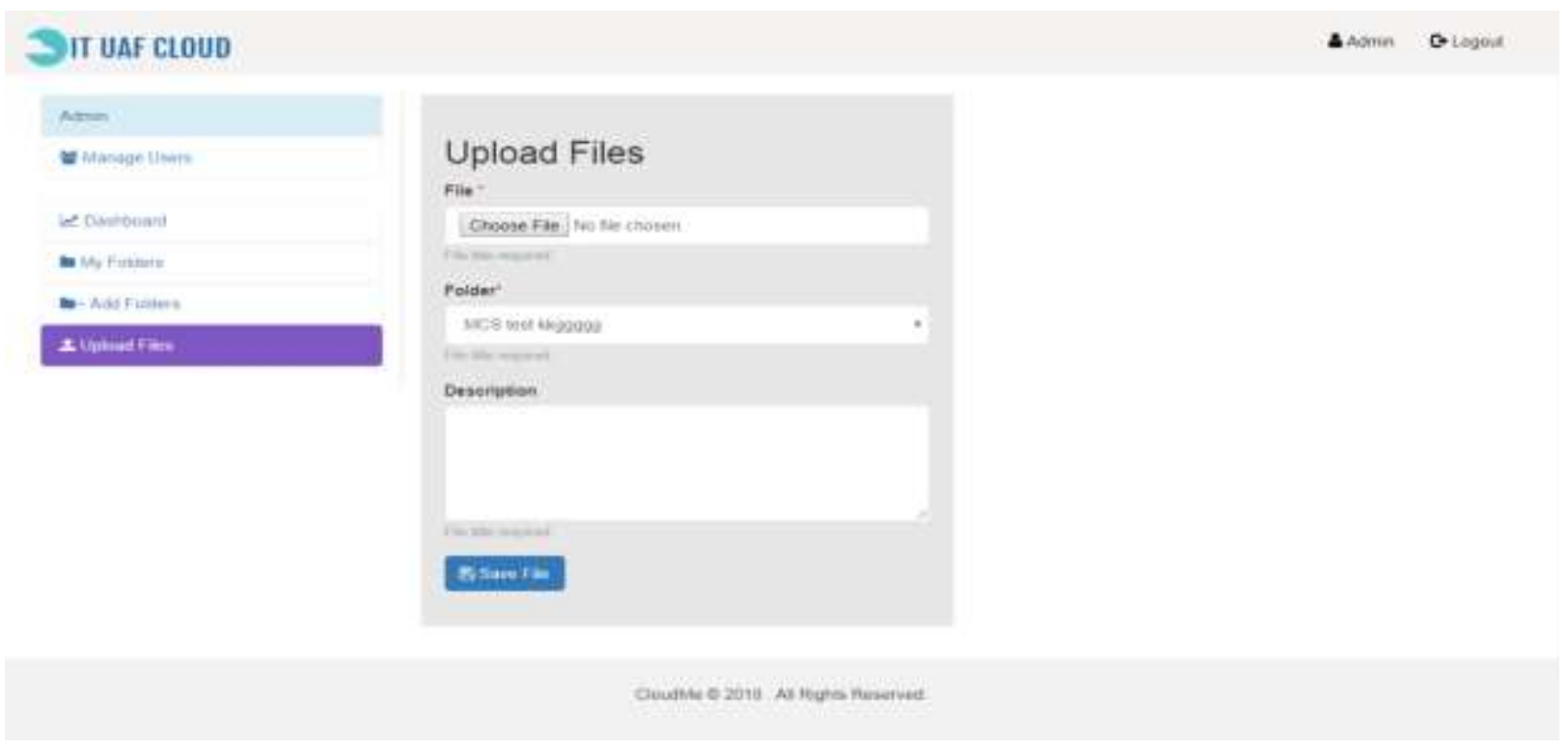

\subsection{Add folders:}

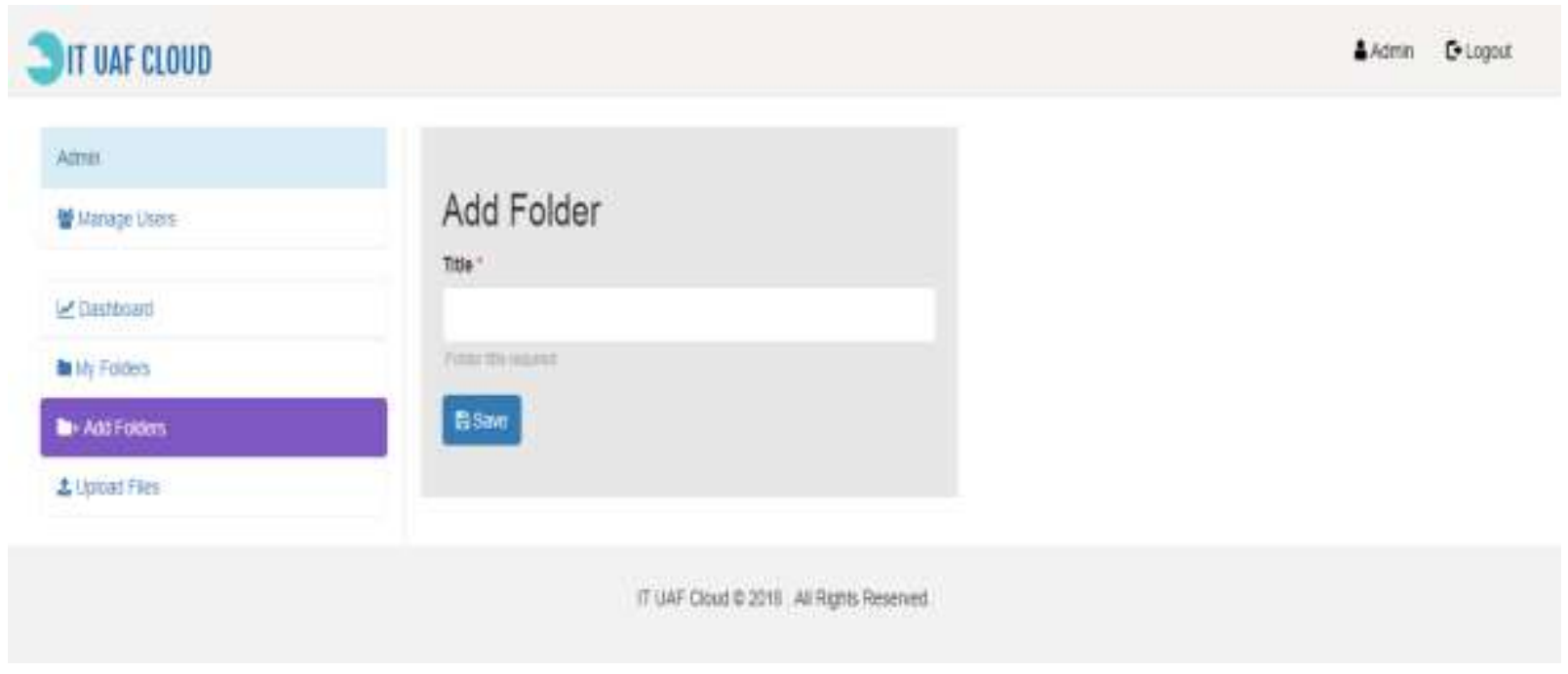

\section{CONCLUSION}

Cloud servers are profoundly secure. It can possibly avoid enormous cerebral pains for some organizations, in light of the fact that once information is put away inside the cloud, it can't be lost. Regardless of whether all organization PCs have a mistake that powers them to reboot and lose the majority of their essential documents and envelopes, their cloud information will in any case be completely open from any gadget, as it's securely put away far from any on location drive.

In any case, no capacity arrangement is great. One of the principle disadvantages of distributed storage is that they are basically organizations in themselves - using a cloud benefit implies putting the majority of your critical information in the hands of a general business, which could fall flat or go bankrupt simply like some other. Utilizing a lesser-known cloud benefit dependably runs the (as a matter of fact little) danger of recovering all information from a server before it close down.

Distributed storage can likewise hold protection concerns, and it's critical that directors read the terms and states of the administration in full before they transfer information as once huge mob. Some cloud administrations may utilize your information to send you focused 
on promotions, and a few administrations may really demonstrate that they possess any information that is put away on their administrations. It's constantly worth twofold checking the little print when joining to such an administration.

Taking everything into account, distributed storage is exceptionally secure, exceedingly available and profoundly effective. There are still a few issues in regards to protection and anchoring information against potential business disappointment, however cloud is developing as a genuine contender for a standout amongst the most total information stockpiling arrangements at present accessible for organizations.

\section{ACKNOWLEDGEMENT}

First author is thankful to Dr. Asif Ali, Sichuan Agricultural University, Chengdu, P.R. China for his technical guidance and suggestions about writing of manuscript.

\section{REFERENCES}

[1] L.M. Vaquero, L. Rodero-Merino, J. Caceres, and M. Lindner, 2009, A break in the clouds: towards a cloud definition, SIGCOMM Comput. Commun. Rev., v. 39, n. 1, p. 50-55.

[2] S. Bhardwaj, L. Jain, and S. Jain, —Cloud Computing: -Cloud Computing: A Study of Infrastructure as a Service (IaaS),\| Int‘' J. Eng. and Information Technology, vol. 2, no. 1, 2010, pp. 60-63.

[3] Spoorthy1, M. Mamatha2, B. Santhosh Kumar3cases "A Survey on Data Storage and Security in Cloud Computing” International Journal of Computer Science and Mobile Computing Vol. 3, Issue. 6, June 2014.

[4] Anisha Tandon "Implementing \& Developing Cloud Computing on Web Application" International Journal of Computer Science and Mobile Computing Vol. 3, Issue. 2, February 2014.

[5] Santosh Kumar and R. H. Goudar "Cloud Computing - Research Issues, Challenges, Architecture, Platforms and Applications" International Journal of Future Computer and Communication, Vol. 1, No. 4, December 2012.

[6] R. Arokia Paul Rajan, S. Shanmugapriyaa "Evolution of Cloud Storage as Cloud Computing Infrastructure Service" IOSR Journal of Computer Engineering (IOSRJCE) ISSN: 2278-0661 Volume 1, Issue 1 (May-June 2012).

[7] Gurudatt Kulkarni, Ramesh Sutar, Jayant Gambhir “Cloud Computing-Storage as Service” International Journal of Engineering Research and Applications (IJERA) ISSN: 2248-9622 www.ijera.com Vol. 2, Issue 1, JanFeb 2012.

[8] Gurudatt Kulkarni, Rani Waghmar, Rajnikant Palwe, Vidya Waykule, HemantBankar, KudilikKoli."Cloud Storage Architecture".IEEE International conference on Telecommunication Systems, Services, and Applications (TSSA).

[9] W. Dawoud, I. Takouna, and C. Meinel, "Infrastructure as a Service Security: Challenges and Solutions," 20107 th International Conference on Informatics and System, March 2010

[10] Liladhar R. Rewatkar \& Ujwal A. Lanjewar, Implementation of Cloud Computing on Web Application”, International Journal of Computer Applications (0975 - 8887) Volume 2 - No.8, June 2010

[11] Sadhana rana, pramod kumar joshi, “ Risk analysis in web applications by using cloud computing”, International Journal of Multidisciplinary Research Vol.2 Issue 1, January 2012, ISSN 22315780

[12] Christian Vecchiola, Suraj Pandey, and Rajkumar Buyya, "High-Performance Cloud Computing: A View of Scientific Applications"

[13] Sultan Ullah and Zheng Xuefeng, “ TCLOUD: A Trusted Storage Architecture for Cloud Computing”, International Journal of Advanced Science and Technology Vol.63, (2014).

[14] H. Zhuo, S. Zhong and N. Yu, "A privacy-preserving remote data integrity checking protocol with data dynamics and public verifiability", IEEE transactions on Knowledge and Data Engineering, vol. 23, no. 9, (2011).

[15] R. G. Ashish and D. M. Bhavsar, "Securing user authentication using single sign-on in Cloud Computing", IEEE Nirma University International Conference on Engineering (NUiCONE), (2011). 
[16] E. C. Liu, X. Zhang, J. Chen and C. Yang, "An Authenticated Key Exchange Scheme for Efficient Security Aware Scheduling of Scientific Applications in Cloud Computing", IEEE Ninth International Conference on Dependable, Autonomic and Secure Computing (DASC), (2011). 